\title{
Exploring the Barriers to Online Learning During the COVID-19 Pandemic. A Case of Pakistani Students from HEls [Higher Education Institutions] ${ }^{1}$
}

Explorando las Barreras al Aprendizaje en Línea durante la Pandemia de COVID-19. Un Caso de Estudiantes Pakistaníes de IES [Instituciones de Educación Superior]

Muhammad Arsalan Nazir and Mohsin Raza Khan²

Bahria University Business School Islamabad Campus, Pakistan

\footnotetext{
1 Recieved: July 9th 2021/ Accepted: November 9th 2021

2 marsalan.buic@bahria.edu.pk; Mohsin.Raza.Khan@gmail.com
} 


\section{Abstract}

The main objective of this study is to explore various barriers preventing students in Pakistani universities from learning online during the COVID-19 pandemic. Applying a qualitative research design, twelve (12) in-depth interviews were conducted with business school students, selected at undergraduate and graduate levels from six (06) universities in Islamabad and Rawalpindi, Pakistan. With thematic analysis, various themes emerged from the interview data. Based on the findings, students who live in rural areas are more affected by on line le arning during the COVID-19 pandemic than students in urban areas due to identified barriers and, most importantly, lack of technology infrastructure. The findings of this study will be helpful for policy makers including government and educational community to conduct and deliver smooth online education in the country during the pandemic.

Keywords: Online barriers; Distance learning; University students; Online Experience; COVID-19; Learning development; Students performance; Developing countries; Pakistan.

\section{Resumen}

El principal objetivo de este estudio es de explorar varias barreras que previenen a los estudiantes de educación superior (universidades) de Paquistán de aprender en línea en esta pandemia de Covid-19. Al aplicar un diseño de investigación cualitativa, doce (12) entrevistas en profundidad se llevaron a cabo con participantes de la escuela de negocios, seleccionados en niveles de pregrado y posgrado. Los datos se recolectaron de seis universidades en Islamabad, Paquistán. Luego de recolectar los datos usando un cuestionario de desarrollo propio, se aplicó un método de análisis temático dentro de la investigación cualitativa para descubrir varias barreras relacionadas con el objetivo de este estudio. Ocho temas emergieron de los datos de las entrevistas, tales como: acceso a internet, el contenido de diapositivas digitales, la percepción de los estudiantes hacia el aprendizaje en línea, cortes de energía durante la pandemia, miedo de los estudiantes a perder notas y su impacto en el empleo, habilidades del profesorado en el uso de la tecnología para enseñar en línea, el estrés de los estudiantes y la salud, y las habilidades para usar herramientas de aprendizaje a distancia. Basado en los hallazgos, los estudiantes que viven en zonas rurales son los más afectados debido a las barreras identificadas y lo más importante a la falta de infraestructura tecnológica. Se han proporcionado oportunidades y recomendación a las autoridades pertinentes para desarrollar y entregar educación en línea fluida en el país durante la pandemia.

Palabras clave: barreras de aprendizaje en línea; estudiantes universitarios; experiencias en virtualidad; COVID-19; países en desarrollo; Paquistán 


\section{Resumo}

O principal objetivo deste estudo é de explorar diversas barreiras que preveem aos estudantes de educação superior (universidades) do Paquistão de aprender online nesta pandemia de Covid-19. Ao aplicar um desenho de investigação qualitativo, doze (12) entrevistas em profundidade foram realizadas com participantes da escola de negócios, selecionados em níveis de graduação e pós-graduação. Os dados foram coletados de seis universidades em Islamabad, Paquistão. Depois de coletar os dados utilizando um questionário de desenvolvimento próprio, aplicou-se um método de análise temático dentro da investigação qualitativa para descobrir diversas barreiras relacionadas com o objetivo deste estudo. Oito assuntos emergiram dos dados das entrevistas, tais como: acesso a internet, o conteúdo de slides digitais, a percepção dos estudantes ao aprendizado online, cortes de eletricidade durante a pandemia, medo dos estudantes a perder notas e seu impacto no emprego, habilidades do professorado no uso da tecnologia para ensinar online, o estresse dos estudantes e a saúde, e as habilidades para utilizar ferramentas de aprendizado à distância. Baseado nas descobertas, os estudantes que moram em áreas rurais são os mais afetados devido às barreiras identificadas e o mais importante à falta de infraestrutura tecnológica. Foram proporcionadas oportunidades e recomendação às autoridades pertinentes para desenvolver e entregar educação online fluida no país durante a pandemia.

Palavras chave: barreiras de aprendizado online; estudantes universitários; experiências em virtualidade; COVID-19; países em desenvolvimento; Paquistão 


\section{Introduction}

he global epidemic of the COVID-19 has spread worldwide, affecting almost every country and territory (Alsoud, 2021). Since its inception in December 2020, at Wuhan, China, it has affected almost 216 countries, with 9,129,146 confirmed cases and 473,797 deaths by the end of June 2020 (WHO, 2020). Countries around the world have warned the public to be responsive. Therefore, public care strategies have included handwashing, wearing face masks, physical distancing, and avoiding mass gatherings (Wang et al., 2021). Lockdowns, including 'smart lock down' and maintenance strategies, have been put in place as a necessary action to flatten the curve and control disease transmission (Bahian et al., 2020). Based on the situation, the World Health Organization declared COVID-19 as a global pandemic, shocked the whole world. The manufacturing and tourism industries in many countries has experienced sharply falling revenues and is an education sector among those most severaly affected by the pandemic (Dhawan, 2020)

In short, this pandemic has changed the entire landscape of the education sector (Baticulon et al., 2021). The impact is enormous, which has affected university learning nowadays, and possibly more in the future. Several schools, colleges, and universities have abandoned face-to-face teaching, resulting in a paradigm shift, and most institutions were being forced to shift from campus-based learning to day-today online teaching overnight (Abbasi et al., 2020). Creating educational disruption everywhere, the COVID-19 pandemic has hampered students' lives and, unfortunately, is likely to have a lasting impact on their future academic lives (Abuhammad, 2020). In this crisis, most university authorities see online education as the panacea for solving problems (Dhawan, 2020). Many institutions are using a blended learning model to cope with the current situation. Top-ranked universities like Harvard, MIT, Stanford, Oxford, and Cambridge, among others, are moving their programs online instead of the campus delivery mode (Zeshan, 2021). Switching to online learning has had many advantages such as flexibility, affordability, $x$ cessibility, an d pe rsonalized $\mathrm{k}$ arning experience. However there are strings attached - it has created a lot more difficulties in universities around the world and has faced several barriers such as infrastructure deficit, extracurricular activities, technical issues, and the most essential provision of adequate resources to ensure effective and efficient dis semination of knowledge (Patricia Aguilera-Hermida, 2020).

By handling the COVID-19 crisis better than many countries around the world, Pakistan, as a developing country, has avoided the need for a complete lockdown and set an example for the world to impose a 'smart lockdown.' THe policies of the Pakistani government have even made the economy work. Despite its proximity to its neighbours, China (12 times the size of Pakistan), where the first COVID-19 infection was found, and India (the second most affected country), Pakistan response to COVID-19 was 
wholistic. Various pharmaceutical and non-pharmaceutical measures have helped Pakistan to curtail the exponential spread of the disease. As a consequence mortality rate due to COVID-19 in Pakistan was very low i.e., 2.1\% compared to Europe, 7.8\%, Asia 2.4\%, and Global 4.7\% (Zeshan, 2021).

As COVID-19 began to spread across Pakistan, HEIs (university) campuses were the first to close. Therefore, just like o ther countries, Pakistani institutions, m ainly HEIs, adopted the hybrid model of learning that combines online educational materials and opportunities for interaction online with traditional place-based classroom methods to minimize the risk of a low quality teaching and learning process (Abbasi et al., 2020). Nevertheless, being a developing country, the issues outweigh the benefits on both ends - the HEIs and their students. The successful transition to online education requires a careful and in-depth understanding of the hidden issues from an administrative and student perspective (Abuhammad, 2020). Therefore, this study explored the barriers to online learning faced by students during the COVID-19 pandemic. This will help to understand their issues and experiences during online learning. The finding of the study will help the policy makers including government, academia and others, to drafT strategies conducive for online learning during pandemics in Pakistan.

\section{Review of Literature}

\section{Challenges and opportunities of online education}

As a result of the pandemic, educational technology has advanced rapidly in many countries: smartphones, tablets, augmented and virtual reality, and affordable broadband internet connectivity, $4 \mathrm{G}$ and $5 \mathrm{G}$ have made it possible to have an online learning process more productive, adaptive, and accessible (Alsoud, 2021). The online learning industry currently has over USD\$ 200 billion and is expected to exceed USD \$ 375 billion by 2026 (Pokhrel and Chhetri, 2021). Higher education institutions worldwide are capitalizing on this technological breakthrough and moving from traditional classroom activities to an online delivery method (Mahyoob, 2020). (Wang et al., 2021) found two types of e-learning, namely asynchronous and synchronous, are mainly compared, but for e-learning to be effective and efficient, instructors (faculty members) and universities (HEIs) must have a comprehensive understanding of the advantages and limitations. Asynchronous learning means that the instructor and course students all interact with the course content at different times and locations. The instructor provides students with a sequence of units that students take according to their schedule. Each unit can use assigned readings or uploaded materials, online quizzes, discussions. The instructor guides the students provide them with feedback and evaluates them as needed (Id, Chen and Chen, 2021). 
On the other hand, synchronous learning means that the instructor and the course students interact with the course content and with each other simultaneously but from different places. The instructor interacts with students in real-time using electronic tools such as Zoom to stream audio, video, and live presentations, and Microsoft Team to host lessons or live meetings, the chat feature of the Team tool to participate in live conversations, and Google Docs to edit documents (Aguilera-Hermida, 2020) simultaneously. Several studies (Baticulon et al., 2021; Fawaz, 2021; Id, Chen and Chen, 2021) have reported the benefits of these delivery methods, such as 1) recorded sessions allowing students to digest session content and/or conduct additional research before asking questions in a focus group, 2) students can access course content and initiate or respond to interactions with the instructor and their peers, when it best fits their schedule, 3) students can review recorded sessions to continue learning, 4) in a live session, only a small number of students will be able to ask questions; in an online discussion group, all students can ask questions or make comments, and 5) allow students to work around unforeseen challenges such as falling ill for a week or facing a family emergency. However, several challenges are to be expected with this online delivery method.

\section{Education in Pakistan during the pandemic}

As the online methods offer various opportunities to several stakeholders, mainly HEIs and education authorities, the method presents many structural, personal and behavioral challenges for faculty and students to successfully adopt and implement online form of learning (Zeshan, 2021). In many countries, due to the COVID-19 pandemic, education technology has advanced and adopted rapidly. In Pakistan however the structure of the education system was a major barrier during COVID-19. To date, almost 22.8 million school-aged children aged 5 to 16 are unable to attend the schools. This is the second-largest number of out-of-school children globally (Abbasi et al., 2020). Add to the misery, the pandemic coincided with Pakistan's struggle to implement a consistent program across all provinces and territories. As coronavirus control measures spread across South Asia, education departments, including federal and interim ministries of education, Higher Education Commission (HEC) of Pakistan, and top-level universities found themselves in dire straits or, in most cases entirely unprepared for online and distance education (Zeshan, 2021). In the past, Pakistan had closed educational institutions due to terrorist attacks and political threats, but there was still no official policy regarding online education (Shahid and Mughal, 2020). Apart from this, developing countries like Pakistan have no robust IT infrastructure to meet the needs of urban and rural populations. In addition, the attitude of the educational community (university administration, faculty, students, and parents) towards this online learning mode is not very positive (Gul and Khilji, 2021). Lack of specific learning space in homes, especially for rural students, parents, 
and HEIs financial technology adoption constraints, lack of personal motivation and professional time management skills, and less academic interaction between students and faculty members are some of the issues to pay attention to make the e-learning experience effective (Shahid and Mughal, 2020).

With all the issues discussed in the literature, there is still an opportunity for HEIs to embrace online education, as COVID-19 has opened many doors of opportunity, and many institutions have adopted e-learning to deal with the pandemic crisis. Therefore, now is the time for stakeholders to design online learning strategies to capitalize on these opportunities.

\section{Research Methodology}

This study used a qualitative research method that involved analyzing qualitative narrative data collected through in-depth interviews with participants. This method was adopted because it involves a detailed and in-depth exploration of the respondent's information and experiences (Rashid et al., 2019). Therefore, in-depth interviews are the most suitable for this type of qualitative study to achieve the stated objective.

\section{Sampling Frame}

In qualitative research, researchers do not have a predetermined sample size but during the data collection phase they must wait to reach a saturation point (Kumar, 2018). Therefore, sampling is the process of selecting a part (a sample) of the largest group (the sampled population) as the basis for estimating or predicting the prevalence of unknown information, situations, or outcomes for the larger group. Therefore, in this study, in total, data was collected from six universities in two cities of Pakistan, Islamabad and Rawalpindi. Three were representing the public sector and three the private sector. The data was randomly collected from these universities. Initially 46 students were selected for the interviews however keeping in mind the time constrains 34 students were screen out. The final sample consist of 12 students who agreed to provide in-depth interviews. The students selected for the final interview fulfilled the sampling criteria i.e. student must have studied at least an entire semester through an online mode. This document is based on student interpretations of various barriers to online learning encountered during the COVID-19 pandemic. The data collection exercise was carried out between October 2020 and March 2021. 


\section{Data Collection Tool}

Due to the pandemic, data was collected using a semi-structured interview method with an open-ended questionnaire as an interview guide through online interviews. The interview questions were developed based on the objective of this study and the existing literature. The interview included questions about participants' backgrounds and current activities during the online semester in COVID-19 and specific questions about issues and obstacles encountered by the interviewee. In order to elaborate on the abstract concepts, we have divided our questions into parts (based on eight 8 themes) using clearer language. We also encouraged respondents to provide concrete examples based on their experiences.

As a result, twelve (12) semi-structured online interviews were directed to collect in-depth information from participants (students). The semi-structured online interviews were recorded manually by handwritten notes and a few audio recordings to be transcribed for further analysis. Interview transcripts were transferred to text format. It begins by labeling and categorizing the codes to determine the latent barriers corresponding to the constructs. Before the interviews, the consent forms were signed by the students and decided to give them enough time to share their experiences regarding the subject's phenomenon freely, so the total interview time was 30-45 minutes, and the authors ensured that all information was received from the students and carefully noted to generate the report.

\section{Data Analysis}

In the semi-structured interviews, handwritten notes and audio transcripts were carefully manually examined for similarities and differences in participants' responses to understand the field data better. Qualitative data from this study was analyzed using thematic techniques. This study used an inductive approach to identify appropriate themes for study from students' explicit responses, as it is considered the most appropriate qualitative approach (Saunders, Lewis and Thornhill, 2009).

After reading the data from the online interview, handwritten notes and audio transcripts were transcribed, codes were then generated after carefully understanding the data. The themes were again compared with all datasets in the form of codes and transcripts to ensure that the developed themes are complete and that all codes have been covered in the analysis process. Several codes such as Internet access, electronic slides etc., were then combined to identify the subthemes (categories) i.e. the availability of uninterrupted broadband Internet access. After careful and in-depth reading and review of the data, themes (e.g. Internet technology access) were explored and selected to draw findings from this study. 


\section{Findings}

The purpose of this study is to explore various barriers preventing Pakistani HEIs (universities) students from learning online in this COVID-19 pandemic. After data collection, thematic techniques analysed the data and several sub-themes were identified. These sub-themes were then classified into eight (8) primary themes based on the codes found within a data set and named as 1) internet technology access, 2) content of digital slides, 3) students' perception towards online learning, 4) power outages during COVID-19 pandemic, 5) students' fear of losing marks and impact on future employment, 6) faculty skills in using technology to teach online, 7) student's stress and health in the COVID-19 pandemic, and 8) student skills to use distance learning tools. In total eight (8) themes were identified based on the codes.

\section{Theme 1 - Internet technology access}

Participants discussed this theme under the sub-theme, namely the availability of uninterrupted broadband Internet access. During the interviews, mixed responses were recorded. Participants in urban areas experienced fewer interruptions in their available internet connections, but participants in rural areas experienced more problems with their low-speed internet connections when attending online lectures during the COVID-19 pandemic. Below are the narratives:

'My place of residence is Islamabad, which is the federal capital, so internet access is available in this area (F-11) of Islamabad. Yes, I have faced interruptions, but these were rare when maintenance was taking place'

'I lost the connection during the online classes, and it affected my performance and results. Once I attended a lecture, my teacher was discussing a very important topic, it was a math topic, and I couldn't learn it on my own. There was a connection problem, and I was unable to attend half of the lecture'

'The quality of the internet around my premises is quite good. However, I faced some interruptions while learning online in the form of virtual classes'

'The most common results of poor internet quality were connectivity issues where I particularly couldn't keep catching up with the course as I wanted'

'During Covid, I had to attend my online classes from Gilgit [rural area]. Unfortunately, Gilgit does not have $4 \mathrm{G}$ or the appropriate internet availability for everyone, and this has affected my online learning. Once, during the defence of my mid-term exam, my internet stopped working, I lost the internet connection and I failed to get grades' 
'I spent most of my time with my family in Abbottabad [rural area] during the COVID-19 pandemic. Therefore, faced with major internet problems during online lectures. Sometimes I would join a class to hear nothing because of the poor internet. Sometimes my assignment is not uploaded to LMS. Sometimes the teacher would ask me a question, but my voice could not reach the other end due to the poor quality of the internet connection'

Lack of access to quality internet connection has emerged as a dominant issue in learning online during COVID-19. Students with high speed internet access were slightly comfortable to learn online as compared to the students who faced poor connectivity issues. The situation was apparent in the remote areas where state of art infrastructure to provide internet access are yet to develop in contrast to metropolitan areas.

\section{Theme 2 - Content of digital slides}

Participants discussed this theme under the sub-theme: understanding the content of electronic slides. Participants believed that teachers who develop technical subjects like math, finance and accounting find it difficult to teach online. Problems faced by the students were content of digital slides, understanding the content in a short time and maintaining the focus. Student complaint that teachers shared the slides only for a few minutes, and it was not possible for the students to easily read and understand the content of the slides in a short time. Moreover, the students lived in the rural areas were unable to focus on slides because of connectivity issues. The slides changes rapidly and they did not remember the content when learning online during the COVID-19 pandemic. Narratives are as below:

'I usually had a hard time understanding some of the content as the teacher had to change the slides when explaining something by drawing it'

'Sometimes it was difficult to understand the technical subjects such as statistics and accounting. It is not at all easy to just go through the slides and when the teacher tries to annotate the technical work and the mathematical solutions on the screen it becomes even more difficult to grasp'

'It happened that even though the content of the slides was in front of us, the medium to deliver the content was not sufficient to understand the topic. Once the teacher explained the topic presented in the slides, but due to the lack of physical presence, some of the content was difficult for us to understand on our own'

'In this context, courses like Fundamentals of Accounting and Financial Management include a set of concepts that revolve around calculations. 
Sometimes the instructor needs to explain these numbers step by step in detail, but many times the slides only mention 1-2 steps or maybe the final answer itself'

'Quantitative subjects involving the digital approach were not very easy to grasp. Theoretical subjects were still easy to understand but the environment was not very conducive to learning. This non conduciveness has made it difficult for us to study analytical subjects in this way'

'Not all courses can be taught online, for example, we studied proposal development in which we had to learn SPSS software and it was very difficult for us to understand through slides, we also studied finance in line but there was no learning at all'

This theme explores the efficacy of digital medium and how it varies across the qualitative and quantitative aspects. It was found that students were comfortable learning qualitative subjects online as it requires less efforts and the slide shared by the instructor were self-explanatory. Students learning quantitative subjects though found it difficult to comprehend the a bject. The dides sha red at tim es hck the rigour required to practice the mathematical subjects. Students found that practicing numerical subjects just by looking online slides was a challenge and it was difficult to grasp.

\section{Theme 3 - Student's perception towards online learning}

Participants discussed this topic under the sub-topic: personal interest in online learning during the COVID-19 pandemic. During the interviews, participants over several semesters were not motivated to learn online and attend online lectures in a pandemic situation due to numerous administrative and technical issues on the part of students and faculty. Participants' experiences are built from these quotes:

'In the online learning some instructors were not lenient. They gave less breaks and it was difficult to stay focused for extended period of time. Moreover, at times the teaching methodology seems static as there was very less interaction between the teacher and student'

'The first online semester went pretty well, but at the start of the second semester I started losing interest as it was more about audio lectures than actual visuals and interactions'

'Due to the online lectures, there is a lack of interest in studying as everything seems boring and sometimes, I am unable to understand what the teacher is saying' 
'Family disturbance even after avoiding it so much, the convenience of being in the comfort zone and the time and snacking flexibility made it very difficult to maintain the interest'

'The online learning was static and it was difficult to stay motivated. Initially I tried to keep my motivation high but during the fifth [online] semester I lost the interest completely. I barely took any classes throughout the fifth semester that was conducted during Covid-19'

'More than one factor has contributed losing my interest in online learning. I couldn't hear the teacher properly and often marked absent. I couldn't concentrate because of various distractions'

'In the 2nd [online] semester, teachers began to focus on online assignments rather than lectures and appropriate subject learning. Most of the assignments did not look like a learning activity but a futile exercise as we were only searching and paraphrasing most of the material. Due to the lack of focus on learning and more on assignments, I started to lose interest'

'Living in a joint family always mean that your microphone can deliver many unwanted voices across the call leading to most embarrassing moments unfortunately, due to which I remained muted most of the time limiting my class participation'

'Disconnecting at intervals would always cause me to miss the most important part of the lecture, making the rest completely incomprehensible. The difficulty in understanding the course is always more than sufficient to demotivate a student and possibly decrease his/her interest'

Lack of one to one connection between teacher and student during online learning and it impact on student attention, interest and motivation was an area on concern. Most of the students lost interest in online learning as there was very little or no interaction between teacher and student. It looks one sided to listen to audio tapes and to understand the lectures. The situation gets worse when the focus was on completing online assignments rather than online learning.

\section{Theme 4 - Power outages during COVID-19 pandemic}

Participants discussed this theme under the sub-theme: frequent power cuts during online learning in COVID-19 pandemic. Mixed responses were gathered from participants due to power outages, participants living primarily in rural areas were most affected and unable to attend online classes daily without any interruptions than those living in urban areas and unable to download online lecture recordings, submit 
online assignments and quizzes, and upload exam paper solutions using CMS/LMS on time. Here are the following quotes:

'Fortunately, I have never encountered this problem while attending online lectures. However, I have heard and seen many of my friends facing this problem because they are residing in rural areas where it is a 24/7 problem or facing the sudden power outage in Islamabad/Rawalpindi which has become a new standard'

'I had to go the extra mile to make sure my mobile data was not lost even in the event of a power failure'

'It [a power outage] happened in quizzes and exams that due to a limited time combined with a power outage, I was unable to answer the questions correctly'

'Sudden power cuts would always disconnect us from online classes, just adding to the difficulties of online learning'

'There were times during exams when the LMS/CMS went down too. Luckily, at home I have a UPS back-up system that provided me with the luxury of powering my Wi-Fi and my laptop computer during online lectures'

'Yes, power outages were not so common in my area, but I have faced it 3-4 times during online classes'

'Not once, not twice, but countless times. There was this time when I was in Swat [rural area] and the light went out due to which I lost the Wi-Fi connection and missed the whole class'

Power outage is one of the burning issues of the country that has adversely impacted the growth of the economy let alone the education sector. Unexpected interruptions due to power outage was critical factor in learning online. Some of the students were very serious about online learning but interruptions beyond their control were not only frustrating but were costing them grades.

\section{Theme 5 - Students' fear of losing marks and impact on future employment}

The participants discussed this theme under the sub-theme: fears of e valuation among students and its impact on employment. In online learning during COVID-19, students believed that they might not be able to secure good grades and this will have an impact on their future employment. Many teachers did not give them good grades which put them in deep stress and employment anxiety. With little practical exposure, 
participants believed that bad grades will further reduce their chances to get desirable job in the future. Below are the narratives:

'Sometimes giving less marks to the students make sense but teachers don't have a visibility teaching online to assess who is working hard'

'It worried me to see how this online learning is affecting our grades. This e-learning is taking us nowhere. We got compromised grades and less future opportunities'

'Due to online assignments, quizzes, and exams, teachers were unable to judge who was making an effort. Many average students copied or asked for help from hardworking students. This made hardworking students looks less efficient and caused them to lose marks and this situation will negatively impact the employment after graduation'

'The main area of interest were grades and GPA for me and my peers, as well as ignoring hands-on learning that deserved more attention'

'Our instructors are quite rigid when it comes to grades and additional favours even though online learning was very stressful and difficult to manage. With zero exposure to the practical learning, I certainly foresee how difficult it would be to find a desirable job in the future'

'I had lower marks on the online exams because of my typing speed. I did all the typing work by myself and didn't take any help from others. At the end it was not enough and I lose marks. I also took new subject i.e. supply chain, which I have very little knowledge. I am afraid what would happen in future when I go for an interview. I have not studied supply chain properly because of online learning and have got very basic knowledge about the subject. I fear of facing the technical question in the interview about the subject on which I have no grip'

'I have been working in the Prestige International HR firm since the start of my MBA. But being the staff member, when interviewing university applicants these days, it is very evident that the students who have gone through the online learning mode are a year behind'

The fear of failure and its consequences on prospective job was palpable from the interviews. There is an aura among students that getting higher grades are linked to securing good jobs. During COVID-19 teachers were reluctant to give good grades to the students because they believed that most of the assignments were plagiarised. As a consequence, they were graded strictly. Students believe they could have obtained good grades if they were taking on campus classes. Some of the students were found extremely dejected and concerned about their prospective jobs as a result of poor grades. 


\section{Theme 6 - Faculty skills in using technology to teach online}

Participants discussed this theme under the sub-theme: faculty members trained to teach students online through electronic tools. Students observed that many teachers lacked formal training to teach online classes during COVID-19. When covid spread and campus learning took place online, many faculty members were unsure of how to use online teaching tools, including MS Team and Zoom. However, later, after using it several times, they knew them. Here are the following quotes:

'Initially, teachers and students weren't sure how to use online mediums [tools], but over time they got better at using it'

'Yes. I felt that. Last year when COVID-19 started and an online change was observed, some of our instructors were unable to use MS Team to take online courses and switched to Zoom. Unfortunately, some of them didn't even know how to use it effectively and even said that they were not very tech savvy and struggled to use these online platforms'

'Initially, instructors had problems using MS Team or Zoom effectively, but in the last online semester they were very proficient in using these tools as everyone learn things with the passage of time'

'One of our teachers didn't know anything about the MS Team or the online sessions. He was sometimes unable to start the lesson or stop some misbehaving students who were using the medium incorrectly to interrupt the learning of others because the teacher did not know how to take control or change the settings of an online session. He used to ask his son to start the class and finish it'

Teaching online was not only challenging for the students but the teachers faced the same issue. One of the challenge faced by the teachers was lack of familiarity in using the online teaching tools like MS Team, Zoom etc. There was no capacity building sessions for the teachers so they equipped themselves for the online tasks. In absence of any formal training on online teaching they were forced to learn it in the hard way - try and error.

\section{Theme 7 - Student's stress and health in the COVID -19 pandemic}

This theme is addressed under the sub-theme: heavy academic workload faced by students. Based on the students perception it was found that due to online learning during the COVID-19 pandemic, most students felt stress at the end of the online 
semester. Indeed, due to the semester's heavy workload, including quizzes, deadlines for assignments, projects, presentations, and exams, which resulted in poor health conditions and, as a result, many students did not do well in final exams. Here are the following narratives:

'There were so many deadlines clashing for different courses which was overwhelming and too much pressure to cope up with'

'With six courses to cover, I felt like every teacher was trying to get things done by assigning daily homework assignments to complete before the next class, so it was a lot of juggling work'

'The whole second online semester turned into a pile of assignments and quizzes that felt like an endless struggle with no real results. The learning was minimal, and it mostly increased stress rather than making us more productive'

'It happened a few times that the students (including me) just joined the online classes and were doing their assignments rather than listening to the lectures'

'Online learning was full of stress and frustration. Being at home and belonging to a Pakistani family, like many other girls, I also must do daily household chores, apart from that many chores which also with inflexible deadlines were far too difficult to handle'

'For some subjects, it was a yes because few teachers did not take the whole scenario seriously at the beginning, which became outrageous for the students at the end of the semester. There were a few teachers who gave us online assignments/presentations/quizzes at the end of the semester like we had nothing else to do'

'Yes, all the time [stress] especially towards the end of the semester when we were still busy with final presentations and project submissions. Usually, we have a week to prepare before exams, but this time we had barely two days to prepare, and I used to study the first paper only'

'I was unable to complete my quizzes and other tasks on time and felt overwhelmed. I was crying because I couldn't keep up with other students and couldn't do my university work on time'

'Stress, because this [e-learning] was a new experience and probably it didn't suit me. I didn't like it and couldn't really focus on the lecture. There were distractions both from our side and from the teacher's side which sometimes seriously annoyed me'

Surprisingly online learning was very stressful for many students. Not meeting 
deadlines, over work, devoid of work life balance and less time for preparation were some of the dominant causes of stress. One of the main drawback emerged of online teaching was student teacher discussion time was replaced by the extra assignments and quizzes. Students were frustrated as they felt they were not learning rather than the focus was on solving quizzes and submitting assignments.

\section{Theme 8 - Student skills to use distance learning tools}

This theme is addressed under the sub-theme: adequate knowledge of students to use distance learning tools. When the COVID-19 pandemic started and convention class learning switched to online learning many students living in rural areas faced difficulties. They were not conversant with online learning, and knows very little about MS Team and the Zoom. These students encountered several issues while using these tools. It took a while to get familiar with the online teaching tools during COVID-19. Here are the following narratives:

'At first it was a bit overwhelming as we weren't exposed to this online learning methodology and didn't know how it worked, but over time we learned and now it's easier to use and access these distance learning tools'

'It happened to me several times that I could not join the MS Team because it was showing an error joining the class or an error while logging in. I think I didn't know how to use it'

'During the first online weeks it was difficult for me to use the tools, but I learned and was able to use them without any difficulty'

'I haven't fully learned how to use these online tools yet; they are very complicated. And I don't even know most of the tools yet'

'At first, I had problems with this [MS Team/Zoom] software, but gradually I started to learn how to use them and gained a strong grip on these distance learning applications'

Students were unaware to use online tools as they have not faced this challenge before. Many students were not even aware of the modern tools like Zoom, MS Team etc. Learning online tools besides the heavy workload was unbearable for many students. 


\section{Discussion}

The main objective of this study was to explore various barriers that prevented Pakistani (universities) students from learning online in this COVID-19 pandemic. Based on the interviews, university students shared mixed responses, especially those who lived in rural and remote areas. It was found that at first when the COVID-19 pandemic started and face-to-face teaching switched to online learning, due to administrative and technical issues, they had to face many challenges to learn online. There are other barriers that hinder students' practical knowledge and have a negative impact on their future employment.

Theme one (1) was internet technology access and explored the barriers in online learning due to the unavailability of internet access. Literature shows that e-learning to work, access to internet technology is imperative. This was apparent when during COVID-19 students learning online require internet access (Alsoud, 2021). With better Internet technology resources available, students can learn online without interruptions (Baticulon et al., 2021). Concerning previous studies, due to the country's poor digital readiness, many educational institutions, including individual customers, are still not equipped with the latest internet technologies (Gul and Khilji, 2021). This is because high-speed internet access is not affordable for many students, especially those residing in rural areas. Even for those with internet access, the quality is not good enough to attend lectures online through MS Team and Zoom software and download/upload online assessments using CMS/LMS. This study found that the unavailability of uninterrupted broadband internet access is considered a significant barrier to online learning among students of higher education institutions in Pakistan. Lack of Internet access and interruptions affected students' online learning as they could not submit assignments on time and, at times, they were unable to attend the classes (Alruwais, Wills and Wald, 2016). This study further found that uninterrupted high-speed internet access is necessary to perform several online assessment tasks that must be taken into account by the competent authorities of internet service providers to adapt the country's e-learning mode to the COVID-19 pandemic.

Theme two (2) was the content of digital slide i.e. what is shared with the online students through power point presentation and other sources. Theme 2 also entails the impact of digital slides on learning online. During COVID-19 the problematic content of digital slides was observed an obstacle for students to learn online easily. Students shared their issues and problems about their lack of understanding on the content of digital slides. Literature shows that the education system in Pakistan has always been the subject of news and criticism, especially the school and university curriculum. Students who graduated from college and entered their first year of the university have always struggled to settle in with the system and teaching methodology (Abbasi et al., 2020). Consistent with the literature current study found 
that during the COVID-19 pandemic, university students could not understand the content of digital slides. Although slides (online presentations) were the only option in Pakistan for distance learning, students believed that this methodology was valid only for theoretical subjects. Most of the students believed that the slides were used for technical courses like Statistics, Accounting, and especially Math, which caused significant problems to learn online. To facilitate e-learning HEIs and faculty members need to adopt an alternative mode, especially for technical subjects. One way could be to solve the question on whiteboard record them and upload on the LMS so that the student can download them at their ease. According to the literature, this problem arises when teachers accidentally have to switch to online teaching mode and they are not technically and mentally ready for it (Pokhrel and Chhetri, 2021; Zeshan, 2021).

Theme three (3) was students perception towards online learning. The theme explain that the perception of students towards online learning was very confusing in Pakistan. The primary cause of this confusion was the absence of one-to-one interaction between teacher and students. In literature about the Pakistani education system, requiring extra grades from teachers to pass or improve students' final grades is expected, however, during the COVID-19 pandemic, there was little or no interaction between teacher and students, and the students were not able to request additional marks considered an important finding of this study. This significantly impacted students' grades as they did not receive additional grades according to their expectations. The situation was complicated when many students lost interest in learning online because they thought some of the courses were boring to learn online, and faculty members were not lenient when grading based on online assignment submissions, quizzes, and exam papers (Abuhammad, 2020). Furthermore, due to the rigor of student assessments, many students lost interest, leading to a negative perception of online learning. Other technical issues such as internet disruptions and course comprehension further lead to students' lower perception of online learning in the COVID-19 pandemic, in line with other literature studies (Fawaz, 2021; Wang et al., 2020).

Power outage remerged as the fourth (4th) theme that hampers the online learning during COVID-19. This problem was also highlighted in literature that the lack of the latest technologies and infrastructure is hampering the growth of many sectors, including education (Nazir \& Roomi, 2021). According to the literature, the availability of stable electricity has played a vital role in e-learning at higher education institutions in developed and western countries (Mahyoob, 2020). However, this study found severe power outages and blackouts in significant parts of Pakistan, including rural and remote areas, and some in urban areas were seen as a major obstacle hindering the e-learning in HEIs of Pakistan during COVID-19. Many students complained that they could have done much better if there was no issue of power outage. They believed that this was one area where they have no control on the situation. Sometimes the students were perfectly prepared for the quizzes, but at the eleventh hour they were 
faced with the problem of the power failure. Ironically there was no schedule for the power outage and it ranges between 5-10 hours in rural areas and 2-4 hour in urban areas. In this scenario, when the power was cut, students could not attend classes, and it could even worsen during online exams. Pakistan's higher education institutions are aware of this challenge, however, due to inflexible exam policies, students suffer as they must rely on expensive alternative electrical backup devices such as UPS and generators to attend classes without interruption and complete the final exams online. In literature (Alruwais, Wills and Wald, 2016) also found that flexible exams policy must be implemented in the COVID-19 pandemic by higher education authorities and universities, making it easier for distant students and allowing them to learn smoothly during blackouts.

Theme five (5) was student fear of losing marks and impact on future employment. THis theme covers the student sentiments towards future employment as a consequence of online learning. Students' fear of losing marks while learning online was found a major barrier in previous studies (Patricia Aguilera-Hermida, 2020; Zeshan, 2021). Students fear that getting lower grades would adversely impact their GPA and could seriously jeopardize their employment opportunities in the future. In Pakistan, business sector usually prefer applicants with good grades, and failing to acquire a high CGPA student could lose the opportunity to get shortlisted (Nazir \& Zhu, 2018). During COVID-19 many instructors used multiple online methods for assessments such as assignments, case study analysis, class participation, quizzes, projects, and exams that students believed teachers were unable to judge who was making an effort and who was not. Further, the lack of interaction between the teacher and student has aggravated the situation. Learning online also means that students are well equipped with the modern teaching techniques, including the use of software, using LMS, and online assessment methods (Gul and Khilji, 2021). However, due to several technical and infrastructure deficit issues, many students failed to get good grades. The primary concerns of students were to get good grades. Getting bad grades in exam is linked with deep stress and employment anxiety (Wang et al., 2020). It is a fact that many faculty members were not able to properly assess the students during the COVID-19. As a result, many students got bad grades. Literature has also supported this fact that online teaching has a negative impact on the students' grade (Pokhrel and Chhetri, 2021). In order to overcome this obstacle, interactive learning and discussion sessions should be introduced in HEIs for the faculty members. THis would be convenient for students and will help them to learn online and achieve good grades. This finding is consistent with previous research which indicate that online assessment has benefits, but errors and ethical issues must be taken into account to make it successful (Bahian et al., 2020; Dhawan, 2020).

It was observed in theme six (6) that faculty skills in using technology to teach online was not exemplary. Although students struggled in learning online, 
teachers were also behind the curve in delivering online lectures. One obvious reason for this inefficiency lies in the fact that the teachers were not given formal training. Previous studies found that the faculty members of HEIs (universities) should have sufficient knowledge and expertise to conduct and execute online teaching mode with adequate know-how of online teaching software, including the MS Team and Zoom (Alruwais, Wills and Wald, 2016). However, this study found that the sudden switch to online education during the COVID-19 pandemic created many problems for students as well as faculty members as they were not trained for online teaching and most of them had very basic knowledge of online teaching software. At time, teachers were asking for help to perform the basic function of MS Team and Zoom, like how to start and end the session, give access to students, record the lecture, etc. This study further found that, without any formal training, many faculty members learned the online teaching tools on their own and got used to them multiple times or with the help of students. It could have saved students and teachers a lot of time and energy if HEI had been provided proper training to faculty members (Id, Chen and Chen, 2021). Similarly, in this unpredictable situation, advanced technology-related training should have been provided to all faculty members of HEIs in Pakistan. The training should have been done before the start of new semester so the faculty is well versed with the basic features of MS Team and Zoom.

Theme seven (7) was about student stress and health during COVID-19. The theme explored that student suffers not only in grades but the health was another hard hit area. A continuous mental stress was not bearable for students and some students were not be able to cope with the situation. The heavy academic workload has been seen as the most common problem for HEI students across the globe during COVID-19 (Shahid and Mughal, 2020). This study found that during the online teaching mode, students were given many assessment tasks with a tight deadline and without any flexibility from the instructors. Many teachers did not take the whole COVID-19 pandemic situation seriously initially, and as the semester progressed, the workload was piled up for the students. At the end of the semester, students had to complete the assignments, assessment, and submit the final project along with presentations, which was frustrating for them. Due to all these sudden assessments, students were annoyed and very concerned about the grade they were likely to receive during the online semester. As a consequence, and due to the heavy academic workload, students got sick, which is seriously associated with academic stress with adverse outcomes such as poor health, anxiety, depression, and poor academic performance. To create a relaxing teaching environment for students, short and practical lesson plans should have been adopted during COVID-19. In addition, the teacher should have short and innovative evaluation criteria to allow the students to work hard and not be stressed. This finding is consistent with a previous study by Id et al., (2021) that the fear of losing marks and the impact on future employment opportunities can lead to stress and health problems for university students. 
Theme eight (8) was students skills to use distance learning tools. The theme documents students weaknesses in using online teaching tools. The inability was mainly attributed to lack of access to professional training. To successfully conduct online sessions during the COVID-19 pandemic, it is not the sole duty of faculty members to learn and execute online teaching tools, but students must have technical skills to use distance learning tools while staying at home (Gul and Khilji, 2021). According to this study, students could not use distance learning tools, including MS Team and Zoom. The COVID-19 has brought a paradigm shift in academia as traditional class room learning was replaced by the online learning. Students were not ready for this change which caused them to quickly learn distance learning tools, which is a serious concern for higher education institutions in Pakistan. Due to a poor understanding of online tools, students suffered a lot in the first semesters and failed to adjust to this new e-learning methodology. However, with time and difficulty with the tools, students gradually learn to use them. The sudden shift to e-learning puts both faculty and students in difficulty. However, relevant distance training on online tools needs to be put in place to overcome user challenges. Many of these suggestions are consistent with the results reported in previous studies (Dhawan, 2020; Baticulon et al., 2021).

\section{Conclusions}

The spread of the COVID-19 pandemic is becoming unstoppable and has already influenced people and countries worldwide. (Id, Chen and Chen, 2021) called for multidisciplinary scientific research to be at the heart of the international response to the COVID-19 pandemic. (Id, Chen and Chen, 2021) provide further evidencebased guidance to respond to promoting the health and well-being of people during the pandemic. To respond to this call, the main objective of this study was to explore various barriers that prevent Pakistani HEIs (universities) business school students from learning online during COVID-19.

The study further explores the stress of students and health issues during COVID-19. This study extends previous studies (Abbasi et al., 2020; Shahid and Mughal, 2020; Zeshan, 2021) and adds to the current literature by highlighting the issues faced by students and faculty members. Many new themes have emerged through qualitative inquiry, such as internet technology access, content of digital slides, student perceptions towards online learning and power outages during COVID-19 pandemic. Higher education institutions must consider such issues to conduct online learning smoothly in the pandemic.

This present study further explored barriers relating to behavioral, personal interest of the students and students' academic stress and health, and most importantly technical and administration. Therefore, the result of present study are important for 
policy making not in Pakistan but worldwide because HEIs will keep using e-learning mode of teaching during the COVID-19 pandemic.

Online education is helpful for students in higher studies, who have completed at least 14-16 years of education from higher education institutions in Pakistan. However, students were concerned about the barriers faced by their peers due to poor administration of HEIs and other technological infrastructure deficits such as power outages, unstable Internet connections, especially in remote and rural areas, and CMS/LMS connection issues when uploading/downloading assessments. Therefore, students believe that the authorities of higher education institutions should resolve the problems related to administration, and government and national telecommunications regulatory authorities should resolve technical issues before embarking on distance learning teaching mode.

Other faculty members should explore an interactive learning methodology while teaching online so students will not be bored and start taking an interest in online learning during the COVID-19 pandemic. HEIs should define an evaluation criterion that is beneficial for students and teachers regarding feedback on online education received from students. This could be done if HEIs have secure and reliable software's for the online teaching mode and quick feedback on student assessments. In addition, students and faculty members need to be trained in technology to take advantage of and reap the benefits of this online learning mode opportunity. 


\section{References}

Abbasi, S. et al. (2020) 'Perceptions of students regarding e-learning during covid-19 at a private medical college', Pakistan Journal of Medical Sciences, 36(COVID19-S4), pp. S57-S61. doi: 10.12669/pjms.36.COVID19-S4.2766.

Abuhammad, S. (2020) 'Barriers to distance learning during the COVID-19 outbreak: A qualitative review from parents' perspective', Heliyon, 6(11), p. e05482. doi: 10.1016/j.heliyon.2020.e05482.

Alruwais, N., Wills, G. and Wald, M. (2016) 'Identifying Factors That Affect the Acceptance and Use of E-Assessment By Academics in Saudi Universities', IJAEDUInternational E-Journal of Advances in Education, 2(4), p. 132. doi: 10.18768/ ijaedu.20012.

Alsoud, A. R. (2021) 'The Impact of COVID-19 Pandemic on Student's E-Learning Experience in Jordan', pp. 1404-1414.

Bahian, M. E. V. et al. (2020) 'Barriers to Online Learning amidst Covid-19 Pandemic', Psychology and Education Journal, 57(9), pp. 2252-2259.

Baticulon, R. E. et al. (2021) 'Barriers to Online Learning in the Time of COVID-19: A National Survey of Medical Students in the Philippines', Medical Science Educator, 31(2), pp. 615-626. doi: 10.1007/s40670-021-01231-z.

Dhawan, S. (2020) 'Online Learning: A Panacea in the Time of COVID-19 Crisis', Journal of Educational Technology Systems, 49(1), pp. 5-22. doi: 10.1177/0047239520934018.

Fawaz, M. (2021) 'RESEARCH ARTICLE E $\otimes$ learning : Depression, anxiety , and stress symptomatology among Lebanese university students during COVID $\bigotimes 19$ quarantine, (May 2020), pp. 52-57. doi: 10.1111/nuf.12521.

Gul, R. and Khilji, G. (2021) 'Exploring the need for a responsive school curriculum to cope with the Covid-19 pandemic in Pakistan', Prospects, (0123456789). doi: 10.1007/s11125-020-09540-8.

Id, C. Y., Chen, A. and Chen, Y. (2021) 'College students' stress and health in the COVID-19 pandemic: The role of academic workload, separation from school, and fears of contagion', 2019, pp. 1-16. doi: 10.1371/journal.pone.0246676.

Kumar, R. (2018) Research methodology: A step-by-step guide for beginners. Sage.

Mahyoob, M. (2020) 'Challenges of e-Learning during the COVID-19 Pandemic Experienced by EFL Learners', Arab World English Journal, 11(4), pp. 351-362. doi: 10.24093/awej/vol11no4.23. 
Nazir, M. A. and Roomi, M. A. (2021) 'Barriers to Adopting Electronic Commerce for Small and Medium-sized Enterprises in Emerging Economies', EMAJ: Emerging Markets Journal, 10(2), pp. 43-55. doi: 10.5195/emaj.2020.203.

Nazir, M. and Zhu, X. (2018) 'E-Commerce adoption factors affecting the SMEs: A Case study investigation of a developing economy-Pakistan', in British Academy of Management Conference September 2018.

Patricia Aguilera-Hermida, A. (2020) 'College students' use and acceptance of emergency online learning due to COVID-19', International Journal of Educational Research Open, 1(September), p. 100011. doi: 10.1016/j.ijedro.2020.100011.

Pokhrel, S. and Chhetri, R. (2021) 'A Literature Review on Impact of COVID-19 Pandemic on Teaching and Learning', Higher Education for the Future, 8(1), pp. 133-141. doi: 10.1177/2347631120983481.

Rashid, Y. et al. (2019) 'Case Study Method: A Step-by-Step Guide for Business Researchers', International Journal of Qualitative Methods, 18, pp. 1-13. doi: $10.1177 / 1609406919862424$.

Saunders, M., Lewis, P. and Thornhill, A. (2009) Research methods for business students. 5 th edn. Edited by P. Hall. Pearson education.

Shahid, R. and Mughal, A. M. (2020) 'E-learning: A way out in COVID-19 Crisis', Journal of Rawalpindi Medical College, 24(3), p. 180. doi: 10.37939/jrmc.v24i3.1486.

Wang, X. Y. et al. (2021) 'Impact of COVID-19 on achieving the goal of sustainable development: E-learning and educational productivity', Economic ResearchEkonomska Istrazivanja , 0(0), pp. 1-18. doi: 10.1080/1331677X.2021.1927789.

Wang, Yixuan et al. (2020) 'Unique epidemiological and clinical features of the emerging 2019 novel coronavirus pneumonia (COVID-19) implicate special control measures', Journal of Medical Virology, 92(6), pp. 568-576. doi: 10.1002/ jmv.25748.

Zeshan, A. (2021) 'Business Students Experiences about Online Learning During Covid 19',RomanianStatisticalReview, (2),pp.48-61. Availableat:https://web-b-ebscohostcom.datubazes.lanet.lv/ehost/pdfviewer/pdfviewer?vid=27\&sid=e2baa3b6-3f464d21-aa50-6d3fdd012bd6\%40pdc-v-sessmgr02. 


\section{Authors}

* Muhammad Arsalan Nazir is an Assistant Professor of Entrepreneurship and Innovation in the Faculty of Marketing and Entrepreneurship at Bahria University of Business School, Islamabad, Pakistan. He holds a PhD in Entrepreneurship and Innovation in Small Business Management from the University of Teesside Business School, UK. He also obtained an MBA in General Management from Cardiff Metropolitan University and MSc in Marketing and Business Management from the University of Bedfordshire School of Business, UK. Currently he is a candidate for Certified Management Accountant (CMA), USA. While working in a private sector based in London, he further has extensive experience in SMEs and entrepreneurship growth in the context of developed and emerging economies in different regions of the world, and in particular in South Asia. He has presented papers at international conferences and his research and publications have specifically focused on the development of digital information and communication technology applications related to e-commerce and innovation in SMEs. The objective is to determine the growth of technological entrepreneurship capacities, then to compare the results with those of other regional actors in the Asian and Western context. He is also a fellow of the British Academy of Management (BAM), UK and a reviewer of several peerreviewed journals.

ORCID: https://orcid.org/0000-0001-5416-9010

Mohsin Raza Khan is a Public Finance Management Specialist with a decade of professional experience in Financial Management, Accounting, and Taxation. He has earned his doctorate in 2018 from Bahria University Islamabad with a major in finance. He has worked on a project to assessed Baluchistan's Revenue Potential and has devised a Revenue Mobilization Strategy for the province. He has also worked with the World Bank as The National Health Financing Consultant. Currently is serving as an Assistant Professor at the Bahria Business School, Bahria University Islamabad. His research areas are PFM, and Health Financing.

ORCID: https://orcid.org/0000-0002-9658-317X

How to reference this article:Nazir, M. A., \& Khan, M. R. (2021) Exploring the Barriers to online Learning During the COVID-19 Pandemic. A case of Pakistani Students from HEIs [Higher Education Institutions]. GIST - Education and Learning Research Journal, 23, 81-106. https://doi.org/10.26817/16925777.1195 